\title{
Evaluation of Seminal Fluid Parameters, Reproductive Hormones and Testicular Biopsy for non-obstructive Azoospermic Patients with Sertoli cell only Syndrome
}

\author{
Naso S. Qhraman*, Muhammad-Baqir M-R. Fakhrildin** and Dhaher H. Bra***
}

*Al-Hakeem Hospital, Ministry of health, **IVF Institute of Embryo Research and Infertility Treatment, Al-Nahrain University, Baghdad, ${ }^{\star * *}$ College of Medicine, Kirkuk University, Kirkuk, Iraq.

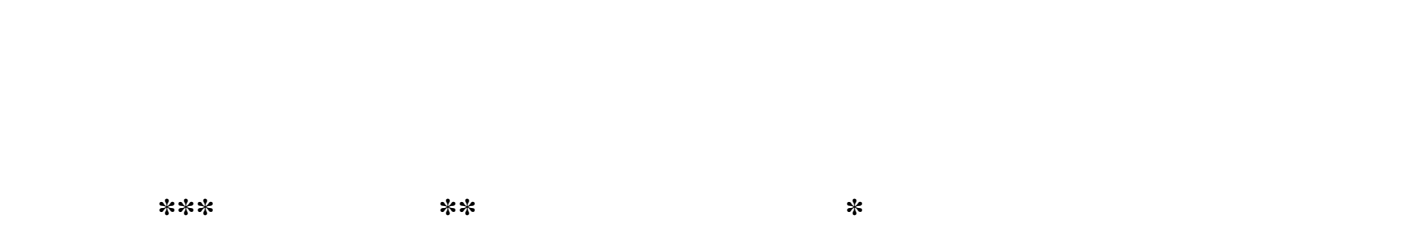

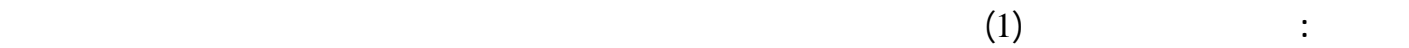

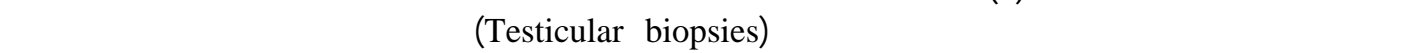

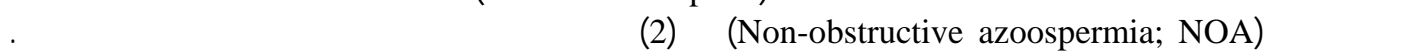

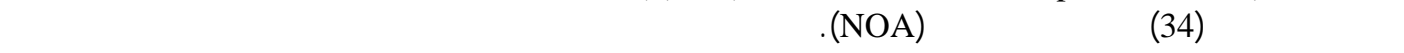

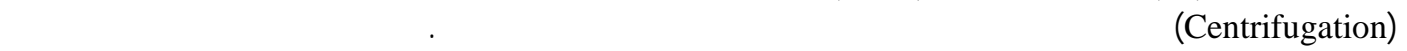

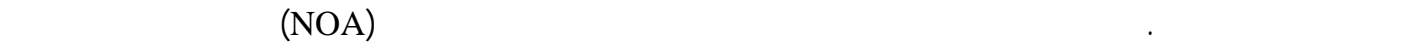

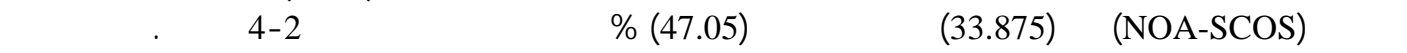

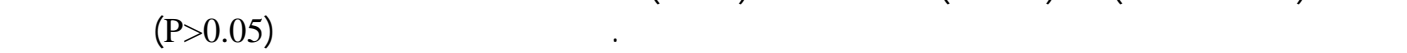

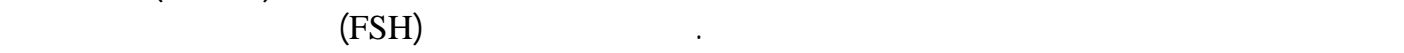

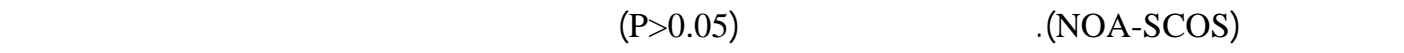

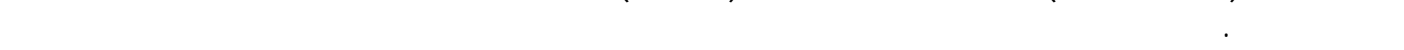

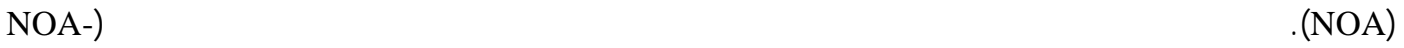
.(SCOS

ABSTRACT: The aims of this study were (i) to determine the seminal fluid parameters, levels of serum reproductive hormones, testicular size and diameter of seminiferous tubules depending on multiple testicular biopsies from non-obstructive azoospermic (NOA) patients, and (ii) to assess the effect of smoking on concentrations of serum reproductive hormones.

Thirty four NOA patients were involved in the present study. The selection of patients was based on an average of 2 pelleting seminal analysis, reproductive hormones profile and diagnostic testicular biopsy. A detailed questionnaire was used to obtain a thorough history from the patients. 


\section{NASO. S. QHRAMAN, MUHAMMAD-BAQIR M.R. FAKHRIDIN and DHAHER H. BRA}

The results of this study showed that the mean age of NOA patients with Sertoli cell only syndrome (SCOS) was 33.875 years, and $47.05 \%$ of NOA patients have had 2-4 years duration of infertility. Macroscopic examination of seminal fluid appeared to have normal values as reported by WHO. Non-significant $(\mathrm{P}>0.05)$ difference was observed for testicular size and diameter of seminiferous tubules between right and left testis. High and abnormal concentrations of serum FSH were registered for NOA patients with SCOS. However, non-significant $(\mathrm{P}>0.05)$ differences were reported for concentrations of serum reproductive hormones between smokers and non smokers. In conclusion, testicular biopsy is the useful and predictable diagnostic tool for NOA patients with SCOS. Further studies are needed to explain the etiology, management and prognosis of NOA patients with SCOS.

KEYWORDS: Azoospermia, sertoli cell, hormones, testicular biopsy.

\section{Introduction}

A zoospermia defined as a complete absence of sperm in the ejaculate, is present in about $1 \%$ of all men (Marmar, 2001) and in about 10-15\% of infertile men (Jarrow et al., 1989). Azoospermia is one of the causes of male infertility factor that can be detected by seminal analysis (Hendin et al., 1998). Non-obstructive azoospermia (NOA) is considered the major contributor to azoospermia, and may be classified into several categories based upon testicular histopathological changes including Sertoli cell only syndrome (SCOS) (Marmar, 2001).

Sertoli cell-only syndrome (SCOS) (so-called germ cell aplasia) is a condition in which the sperm producing-cells are no longer present in the testicles. In complete germ cell aplasia, the tubules are reduced in diameter and contain only Sertoli cells but no other cells involved in spermatogenesis (Nistal et al., 1990; Anniballo et al., 2003). SCOS also can be focal with a variable percentage of tubules containing germ cells (Sigman and Howards, 1998).

The testicular biopsy is a useful adjunct in the male infertility evaluation because it can provide a more precise clinical diagnosis, and assist in treatment selection for several infertility disorders. Testicular biopsy is most useful in differentiation between obstructive and non-obstructive azoospermia (Turek et al., 1995). Abnormalities of seminiferous tubule architecture and cellular composition can be assessed and categorized into several patterns that aid in therapeutic decision-making (Turek, 2000). In addition, physical examination should note testicular size and consistency, secondary sex characteristics, including body habitus, hair distribution, gynecomastia, consistency of the epididymis, presence of a varicocele and masses on digital rectal examination. The initial hormonal evaluation should include measurement of serum testosterone and FSH levels (Sigman and Howard, 1998). Therefore, the aims of this study were (i) to determine the seminal fluid parameters, levels of serum reproductive hormones (including FSH, LH, testosterone and prolactin), testicular size and diameter of seminiferous tubules (ST) depending on multiple testicular biopsies from non-obstructive azoospermic (NOA) patients, and (ii) to assess the effect of smoking on concentrations of serum reproductive hormones.

\section{Subjects, materials and methods}

\subsection{Subjects}

This study was carried out on non-obstructive azoospermic (NOA) patients who complained from primary infertility and attended the infertility clinic at Azadi general hospital, Kirkuk governorate. The total number of NOA patients involved in this study was 34. The study extended from October, 2004 to October, 2005. Selection of azoospermic patients was based on diagnosis of azoospermia in which at least two standard semen samples were found to be devoid of sperm cells and the absence of spermatozoa. Azoospermia was confirmed by a study of the sediment after centrifugation of semen at $2500 \mathrm{rpm}$ for 10 minutes (sperm pelleting) (Hendin et al., 1998). 


\section{EVALUATION OF SEMINAL FLUID PARAMETERS}

The time interval between the two consecutive semen samples was not less than 7 days and did not exceed three months (WHO, 1999). The clinical data of NOA patients with SCOS are shown in Table 1.

The criteria applied for patient selection were proper history taking, physical examination and reproductive hormones levels assessment. Each patient should have a report of histological examination of a diagnostic testicular biopsy.

Table 1. Clinical data of NOA patients with SCOS * involved in this study

\begin{tabular}{|c|c|}
\hline Parameters & Data \\
\hline Age (year) & $33.875 \pm 0.802$ \\
\hline Duration of infertility (range: $>1.0-13.0$ year) \\
\hline$<2$ year & $6(17.54 \%)$ \\
\hline $2-4$ years & $16(47.05 \%)$ \\
\hline $5-6$ years & $3(8.82 \%)$ \\
\hline $7-8$ years & $2(5.88 \%)$ \\
\hline $9-10$ years & $2(5.88 \%)$ \\
\hline \multicolumn{2}{|c|}{ Seminal fluid parameters } \\
\hline Liquefaction time (min.) & $5(14.70 \%)$ \\
\hline Volume (mL) & $29.76 \pm 0.98$ \\
\hline Viscosity & $2.467 \pm 0.16$ \\
\hline pH & Normal (leave the pipette as \\
\hline
\end{tabular}

* Number of patients: 34 .

\subsection{Laboratory tests}

\subsubsection{Seminal fluid collection and analysis}

Semen samples were collected by masturbation after 3 to 5 days of abstinence into a dry, clean and sterile Petri dish labeled with the name and age of the patient, period of abstinence and the time of collection. The specimens were placed in the incubator at $37^{\circ} \mathrm{C}$ to allow the semen liquefaction (Silverberg and Turner, 2001). The specimen was examined in detail macroscopically and microscopically including semen liquefaction time, volume viscosity, $\mathrm{pH}$ and sperm concentration. Because of the fluctuation of semen parameters, each patient had at least two seminal fluid analyses. WHO criteria for normal semen values were applied (WHO, 1999).

\subsubsection{Hormonal assay}

A blood sample was drawn and collected in a clean, disposable plastic tube. Concentrations of serum FSH, LH, prolactin and total testosterone were measured using miniVIDAS apparatus (VIDAS 12, 1992, Biomerieux Company, France), through an enzyme linked fluorescent assay (ELFA) technique.

\section{Open diagnostic testicular biopsy}

\subsection{Procedure}

The procedure applied for open diagnostic testicular biopsy was described by Qhraman (2006). However, open diagnosed testicular biopsy was performed under general anesthesia. The testis should be held with the ventral testicular side facing the surgeon, the skin held tightly and the epididymis held between the left-hand index and the middle finger to fix the testicle and keep the epididymis away from the operation. After incising 
the skin, the dartos muscle was incised, the edges dissected away from the tunica vaginalis and separated with small retractors. A tiny incision was made in the tunica albugenia and a small piece of the protruded testicular tissue was taken with a fine pair of scissors and placed in Bouin's solution to preserve it. The cut edges of tunica albugenia were sutured with fine 2 or 3 zero chromic cat gut, leaving one side of the thread long to be held with artery forceps and used as a means of retraction as the first biopsy was taken from the middle zone.

After the three biopsies, the tunica vaginalis was sutured separately by cat gut in a way that prevented any possible bleeding which might lead to hematoma and infection. When the testes were small, only two or even one biopsy was taken. The samples were sent for histopathological examination.

\subsection{Preparation the sections for histopathology}

The method for the preparation of histological sections for histopathology was slightly modified from work done by Bancroft and Stevens (1982), and mentioned by Qhraman (2006) in detail.

\subsection{Histological assessment of spermatogenesis}

Histological evaluation was done for the prepared specimens. Germ cell elements were quantitatively assessed. At least 15 transverse sections of seminiferous tubules were examined in each biopsy to see the size and proportion of tubules in the biopsy. The diameter of seminiferous tubules was measured using an ocular micrometer. The diameter of at least 12 sections of seminiferous tubules was measured for each slide.

The seminiferous tubules (ST) with or without germ cells were observed, number, type, distribution, localization; and morphology of germinal epithelium within the seminiferous tubules were observed. Sertoli cells, Leydig cells, degenerating cells, tubular diameter and thickness of tubular basement membrane, all were checked. The pattern of Sertoli cell-only syndrome, characterized by seminiferous tubules occupied by Sertoli cells only with absence of germ cells was recorded.

\section{Statistical analysis}

Computerized statistical analyses were performed using SPSS (Statistical Package of Social Science, version 12). Frequency distribution, percentage and mean \pm standard error of the mean (SEM) for selected variables were calculated. Paired student t-test and one way ANOVA test were used to assess the statistical significance of the difference in the means of different groups. $P$ value less than 0.05 was considered statistically significant (Sorlie, 1995).

\section{Results}

Thirty four NOA patients with mean age 33.8 years, and duration of infertility ( $1-13$ years) were involved in the present study (Table 1). From same table, $47 \%$ of NOA patients with SCOS (NOA-SCOS) have 2-4 years duration of infertility while the lowest percentages (10.41\%) were recorded for 5-6 years and 7-8 years durations of infertility. Macroscopic parameters of seminal fluid observed normal values (Table 1). Varicocele and orchidopexy were the most common risk factors affecting NOA-SCOS (Figure 1). 


\section{EVALUATION OF SEMINAL FLUID PARAMETERS}

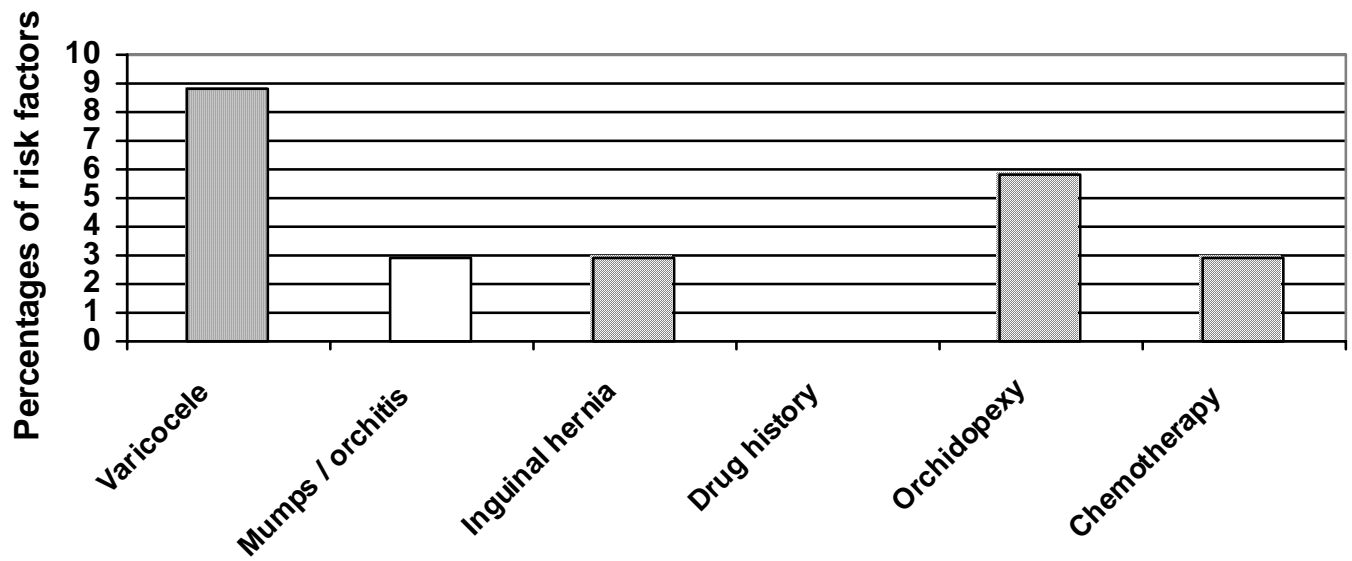

Risk factors

Figure 1. Percentages of NOA with SCOS complaining from different risk factors for a sample of 34 patients.

Non-significant $(\mathrm{P}>0.05)$ differences for testicular size and diameter of seminiferous tubules were reported between right and left testis of NOA-SCOS. The mean testicular size and diameter of seminiferous tubules were $3.143 \mathrm{~cm}$ and $118.756 \mu$; respectively (Table 2).

Table 2. Mean testicular size and diameter of seminiferous tubules (Rt, Lt and mean within both testes)* of NOA patients with SCOS for a sample of 34 patients (Data are means \pm SEM).

\begin{tabular}{|c|c|c|c|}
\hline \multirow{2}{*}{ Parameters * } & \multicolumn{2}{|c|}{ Testes } & \multirow[t]{2}{*}{ Mean within both testes } \\
\hline & Right & Left & \\
\hline Testicular size $(\mathrm{cm})$ & $\begin{array}{c}3.188 \\
+0.114\end{array}$ & $\begin{array}{c}3.097 \\
+0.123\end{array}$ & $\begin{array}{c}3.143 \\
+0.146\end{array}$ \\
\hline Diameter of seminiferous tubules $(\mu)$ & $\begin{array}{c}125.879 \\
+3.27\end{array}$ & $\begin{array}{c}123.784 \\
+2.93\end{array}$ & $\begin{array}{c}118.756 \\
+3.79\end{array}$ \\
\hline
\end{tabular}

* Non-significant $(\mathrm{P}>0.05)$ difference.

Higher levels of serum FSH, LH and prolactin were observed in NOA-SCOS, and combined with low level of serum testosterone as compared to normal ranges of WHO report (Figure 2), although, non-significant $(\mathrm{P}>0.05)$ differences for concentrations of serum FSH, LH, testosterone and prolactin were obtained between smokers and non smokers patients (Figure 3). 
NASO. S. QHRAMAN, MUHAMMAD-BAQIR M.R. FAKHRIDIN and DHAHER H. BRA

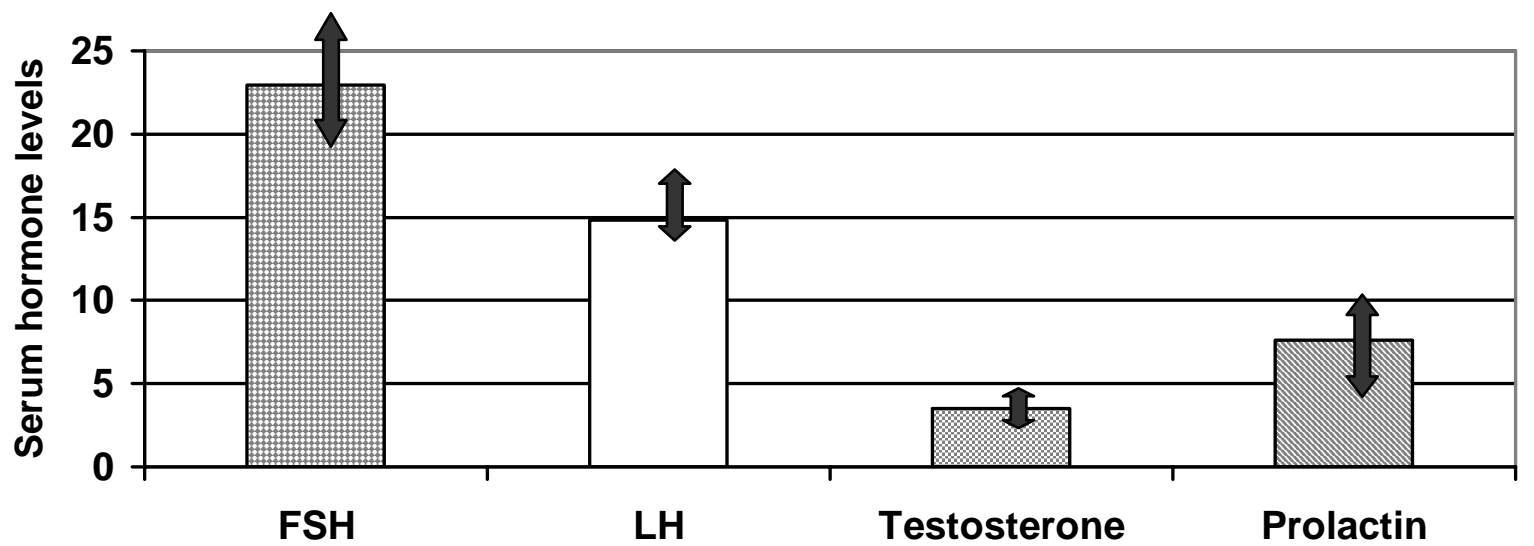

Types of Reproductive Hormones

Figure 2. Mean serum levels of FSH (mIU/ml), LH (mIU/ml), testosterone (ng/ml) and prolactin (ng/ml) of NOA patients with SCOS for a sample of 34 patients. (Data are means \pm SEM).

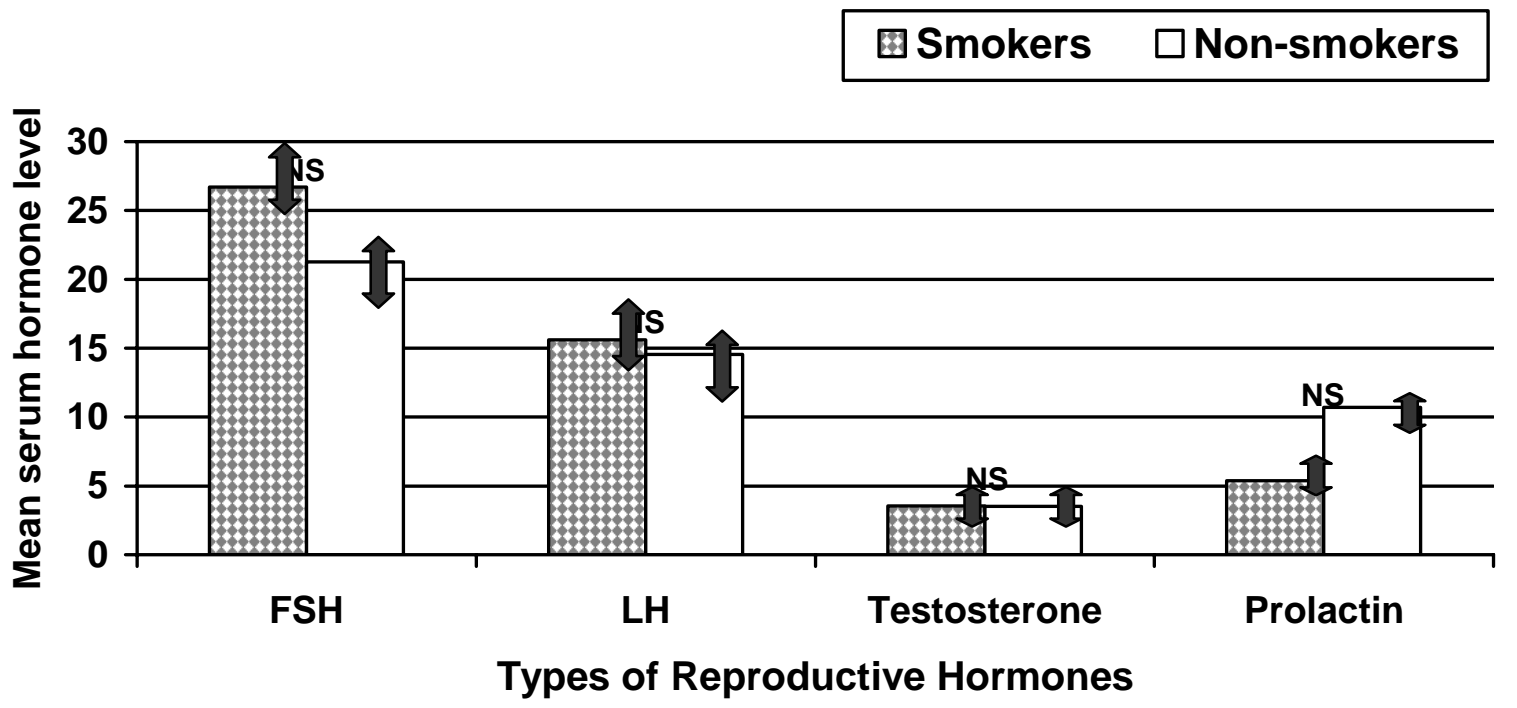

Figure 3. Mean serum levels of FSH (mIU/ml), LH (mIU/ml), testosterone (ng/ml) and prolactin (ng/ml) of NOA patients with SCOS divided according to smoking habit for a sample of 34 patients. (Data are means \pm SEM). * Non-significant $(\mathrm{P}>0.05)$ difference. 


\section{EVALUATION OF SEMINAL FLUID PARAMETERS}

\section{Discussion}

Thirty four non-obstructive azoospermic patients (mean age: 33.87 years) complaining from SCOS (NOASCOS patients) were enrolled in this study. Medical and surgical history, seminal fluid parameters, reproductive hormonal profile and histopathological features of testicular biopsies were evaluated. In the present study, the highest percentage (47.05 \%) of NOA-SCOS patients had 2-4 years duration of infertility. However, there was gradual reduction in the percentages of NOA-SCOS patients as duration of infertility progressed. Several explanations for this result may be relevant. The start of infertility treatment after one year of marriage causes accumulation of infertile patients throughout the first two years of treatment. While other causes reduce numbers of NOA-SCOS patients including increased years of infertility without fecundation and hope, then an increased psychological stress and financial cost. Furthermore, increase in age of NOA-SCOS patients combined with failure of medical management may also be relevant.

In relation to the risk factors associated with NOA-SCOS patients, varicocele has the higher frequency of those assessed. WHO (1992) found a non-significant difference in the occurrence of azoospermia among infertile males with or without varicocele. Tulloch (1995) considered varicocele as the most common identifiable cause of male subfertility. However, Pasqualotto et al., (2003) observed a common association between azoospermia and varicocele as a result of generalized impairment in sperm production.

The results of this study indicate that the mean testicular size $(3.143 \mathrm{~cm})$ for NOA-SCOS patients was within the lower limit of the normal range (McAnnich, 2000). Since seminiferous tubules (STs) form the 80-85 $\%$ of the testicular mass (Heath and Young, 2000) reduced testicular size, in our study, may be attributed to seminiferous tubules (STs) that are either destroyed or empty of different spermatogenic cells. Sharif (2000) reported that the small testicular volume may suggest an impairment of STs especially if the small volume is associated with raised FSH concentration. A reduced bilateral testicular size associated with normal ejaculate volume and raised concentration of circulating FSH, is considered to be a reliable indicator of germinal epithelial damage and non-obstructive azoospermia (Battaglia et al., 2001).

From testicular biopsies, the mean diameter of seminiferous tubules (STs) (118.756 $\pm 3.79 \mu \mathrm{m})$ revealed a significant reduction in diameter as compared to normal diameter of STs range (150-200 $\mu \mathrm{m})$ (Junqueira et al., 2003). The diagnosis of SCOS is made when a single biopsy is histologically empty (except for Sertoli cells) while seminiferous tubules and no other pathological findings. Although there are many cases of non-obstructive azoospermia that have been classified as SCOS, 100\% occurrence of SCOS is very rare indeed (Silber et al., 1995). Sigman and Howards (1998) noticed that the diameter of STs is reduced and may show some thickening of the tubular basement, in addition to slightly elevated serum FSH (Leifke et al., 1997). Many authors mentioned that the testicular histology in case of complete SCOS will show normal Leydig cells, no germ cells and narrow tubules (Behre and Bergmann, 2003). A non-significant ( $\mathrm{P}>0.05)$ difference was found in the diameter of STs between right and left sides. A similar result was reported by other researchers (Turek, 2000).

Regarding the macroscopic results of seminal fluid parameters in the present study, normal means were obtained according to the criteria of WHO (1999). Most seminal fluid is produced from male accessory glands which are affected by level of testosterone. In turn, macroscopic parameters of seminal fluid are highly affected by testosterone concentration (Martini, 2001). In the present work, results of the hormonal profile indicated that low levels of serum testosterone are associated with elevation of serum LH. These results are correlated with results of macroscopic parameters of seminal fluid, indicating normal Leydig cell function (Behre and Bergmann, 2003). Sigman and Howards (1998) mentioned that the Leydig cells are present, usually normal but on occasion are found to be reduced in size and number.

In the present study, investigation of the hormonal profile for NOA-SCOS patients showed elevation of serum gonadotropins and prolactin as compared to the normal criteria of WHO (1999). Leifke et al. (1997) observed that infertile men with SCOS have highly elevated serum FSH relating to the degree of histological damage, and extremely low levels of inhibin B (Hu and Huang, 2002). However, elevated serum FSH associated with normal or low serum testosterone is consistent with primary testicular failure (Hauser, 1995). Marked elevation of serum FSH to greater than two times the upper limit of normal is diagnostic of abnormal 


\section{NASO. S. QHRAMAN, MUHAMMAD-BAQIR M.R. FAKHRIDIN and DHAHER H. BRA}

spermatogenesis. Therefore, a diagnostic testicular biopsy is not necessary in patients with markedly elevated FSH (Jarrow et al., 2002). The mild elevation in level of serum prolactin observed in NOA-SCOS patients leads to reproductive dysfunction. Hyperprolactinemia causes low testosterone secretion and leads to disorder of spermatogenesis (Biller, 1999). However, pre-testicular causes are endocrine abnormalities that adversely affect spermatogenesis that are relatively rare and account for $1 \%$ of azoospermia (Jarrow et al., 1989).

Non-significant $(\mathrm{P}>0.05)$ differences in hormonal profiles were observed between smokers and nonsmokers NOA-SCOS patients. Light to moderate cigarette smoking causes permanent and undetectable damage for functions of endocrine cells. However, the results of this study are similar to the results of some authors and contrast to others. Many studies have assessed the association between smoking and a variety of male reproductive hormone levels with some conflicting results (Istvan et al., 1995). While it is likely that smoking alters male hormone levels, the relationships are not well characterized (Stillman et al., 1986). Cigarette smoke contains several chemical agents, many of which are carcinogenic or mutagenic (Kunzle et al., 2003). These agents affect the production and function of normal sperm by reduction in testosterone concentration in testicular tissue as a consequence of impaired Leydig cell function by direct effect of inhaled nicotine and carbon monoxide on testicular tissue (Zavos et al., 1999).

In conclusion, the open testicular biopsy was found to be practical, informative and valuable diagnostic tool for NOA patients. More studies are needed to explain the etiology, management and prognosis of NOA patients with SCOS.

\section{References}

ANNIBALLO, R., UBALID, F. and TESARIK, J. 2003. Functional status of the Sertoli cells in azoospermic men. Fertil. Steril, 79: 237-238.

BANCROFT, J.D. and STEVENS A. 1982. Theory and practice of histological techniques. $2^{\text {nd }}$ Edition. Churchill, Livingston, London. pp. 110-111.

BATTALGIA, C., GIULIANI, S., REGNANI, G. and MODGAR, I. 2001. Intratesticular Doppler flows, seminal plasma nitrites/nitrates and non- obstructive sperm extraction from patients with obstructive and non-obstructive azoospermic. Fertil. Steril, 75: 1088-1094.

BEHRE, H.M. and BERGMANN, M. 2003. Primary testicular failure. In: Endocrinology of Male reproduction. www.endotext.com.

BILLER, B.M. 1999. Hyperprolactinemia. Int. J. Fertil, 44: 74-77.

HAUSER, R. 1995. Fertility in cases of hypogonadotropic azoospermia. Fertil. Steril, 63: 631-636.

HEATH, T.W. and YOUNG, B. 2000. Male reproductive System. In: Functional Histology. Horne, T. (ed.); Churchill Livingstone, London. $4^{\text {th }}$ ed.; pp. 324-333.

HENDIN, B.N, BATEL, B. and LEVIN, H.S. 1998. Identification of spermatozoa and round spermatids in the ejaculates of men with spermatogenic failure. Urology, 51: 816-819.

HU, Y.A. and HUANG, Y.F. 2002. A serum marker of spermatogenesis-inhibin B. Zhonghua-Nan-Ke-Xue, 8: 57-60 (Medline).

ISTVAN, J.A., BUIST, A.S., HESS, D.L. and VOELKER, H. 1995. Relationship of smoking cessation and nicotine gum use to salivary androstenedione and testosterone in middle-aged men. Metabolism, 44: 90-95. (Medline)

JARROW, J.P., ESPELAND, M.A. and LIPSHULTZ, I.L. 1989. Evaluation of the azoospermic patients. J. Urol, 142: 62-65.

JARROW, J.P., SHARLIPM, D.I., BELKER, M.A. and LIPSHULTZ, L.I.. (2002): Best Practice Policies for male infertility. J. Urol, 167: 2138-2144.

JUNQUEIRA, L., CARNEIRO, J. and KELLEY, R.O. 2003. Male Reproductive system. In: Basic Histology. Foltin, J. ; Lebowidz, H. and Boyle, B. (eds.); Appleton and Lange, Stamford.10 ${ }^{\text {th }}$ ed. pp. 406-411.

KUNZLE, R., MUELLER, M.D. and HANGGI, W. 2003. Semen quality of male smokers and spontaneous sperm agglutination in men from infertile couples. Med. Assoc. J, 78: 89-93. 


\section{EVALUATION OF SEMINAL FLUID PARAMETERS}

LEIFKE, E., SIMONI, M., and KAMISCHKE, A. 1997. Does the gonadotrophic axis play a role in the pathogenesis of Sertoli cell-only syndrome? Int. J. Androl, 20: 29-36.

MARMAR, J.L. 2001. The Diagnosis and Treatment of Male in the New Millennium. Int. J. Fertil, 46: 116-129.

MARTINI, F. 2001. The Reproductive System. In: Fundamentals of Anatomy and Physiology. Disney, H. (ed.); Printice Hall, New Jersey. $5^{\text {th }}$ ed. pp. 1017-1034.

MCANNICH, J.W. 2000. Disorders of the testis, scrotum and spermatic cord. In: Smith's General Urology. Tanagho, E.A. and McAnnich, J.W. (eds.); Lange Medical Books/McGraw-Hill, USA. 15 ${ }^{\text {th }}$ ed.; pp. 684-693.

NISTAL, M., JIMENEZ, F. and PANIAGUA, R. 1990. Sertoli cell types in the Sertoli-cell-only syndrome: Relationships between Sertoli cell morphology and etiology. Histopathology, 16: 173-180.

PASQUALOTTO, F.F., LUCON, A.M.. and HALLAK, J. 2003. Induction of spermatogenesis in azoospermic men after varicocele repair. Hum. Rprod, 18: 108-112.

QHRAMAN, A.S. 2006. Materials and Methods. In: A comparison study on non obstructive azoospermic patients: Spermatogenic maturation arrest versus Sertoli cell only syndrome. High Diploma Thesis, IVF Institute of Embryo Research and Infertility Treatment, Al-Nahrain University. Baghdad, Iraq. pp. 46-55.

SHARIF, K. 2000. Advances in the treatment of male factor infertility. In: Recent advances in Obstetric and Gynecology. Mosby Year Book. pp. 142-157.

SIGMAN, M. and HOWARDS, S. 1998. Male Infertility. In: Campbell's Urology. Campbell, M.F. and Walsh, P.C. (eds.); W.B. Saunders Company, Philadelphia. $7^{\text {th }}$ ed.; Vol. 2; pp. 1278-1330.

SILBER, S.J., VAN STEIRTEGHEM, A.C. and DEVORITY, P. 1995. Sertoli cell only revisited (editorial). Hum. Rprod, 10: 1031-1032.

SILVERBERG, K.M and TURNER, T. 2001. Evaluation of sperm. In: Textbook of Reproductive Techniques, Laboratory and Clinical Perspectives. Gardner, D.K.; Weissman, a.; Howles, C.M.; and Shoham, Z. (eds.); Martin Dunitz Ltd.; London. pp. 61-74.

SORLIE, D.E. 1995. Medical biostatistics and epidemiology: examination and Board review. $1^{\text {st }}$ ed. Appleton and Lange, Norwalk, Connecticut. pp. 47-88.

STILLMAN, R.J., ROSENBERG, M.J. and SACHS, B.P. 1986. Smoking and reproduction. Fertil. Steril,46: 545-566.

TULLOCH, W. S. 1995. Varicocele in subfertility: Results of treatment. Br. J., Urol, 2: 356-358.

TUREK, P.J., MAGANA, J.O. and LIPSHULTZ, L.I. 1995. The clinical characteristics of 82 patients with Sertoli cellonly testis histology. Fertil. Steril, 64: 1197-1201.

TUREK, P.J. 2000. Male Infertility. In: Smith's General Urology. Tanagho, E.A. and McAnniched, J.W. (eds.), Lange Medical Book / McGraw-Hill, Beirut, Lebanon. 15 ${ }^{\text {th }}$ ed.; pp. 750-787.

WORLD HEALTH ORGANIZATION (WHO) 1992. The influence of varicocele on parameters of fertility in a large group of men presenting to infertility clinic. Fertil. Steril, 57: 1289-1293.

World health Organization (WHO) 1999. WHO laboratory manual for the examination of human semen and sperm cervical mucus interaction. $4^{\text {th }}$ ed.; New York; Cambridge University Press; pp. 4-59.

ZAVOS, P.M., ZARMAKOUPIS, C.N. and ZARMAKOUPIS ZAVOS, P.N. 1999. The impact of cigarette smoking on human reproduction: its effects on female and male fecundity. Mid. East Fertil. Soci. J, 4: 94-101.

Received 25 July 2006

Accepted 31 October 2006 